\title{
Acetylcholinesterase mRNA Level and Synaptic Activity in Rat Muscles Depend on Nerve-Induced Pattern of Muscle Activation
}

\author{
Janez Sketelj, ${ }^{1}$ Neva Črne-Finderle, ${ }^{1}$ Borut Štrukelj, ${ }^{2}$ Jože V. Trontelj, ${ }^{3}$ and Dirk Pette ${ }^{4}$ \\ 1/nstitute of Pathophysiology, School of Medicine, University of Ljubljana, 1000 Ljubljana, Slovenia, 2Jozef Stefan Institute, \\ 1000 Ljubljana, Slovenia, 3/nstitute of Clinical Neurophysiology, University Medical Center, 1000 Ljubljana, Slovenia, and \\ ${ }^{4}$ Fakultät für Biologie, Universität Konstanz, D-78457 Konstanz Germany
}

\begin{abstract}
Acetylcholinesterase (AChE) mRNA levels are severalfold higher in fast rat muscles compared with slow. We hypothesized that AChE mRNA levels and AChE activity in the neuromuscular junction depend on a specific nerve-induced pattern of motor unit activation. Chronic low-frequency stimulation, mimicking the activation pattern in slow muscles, was applied to fast muscles in rats. Molecular forms of AChE were analyzed by velocity sedimentation, and AChE mRNA levels were analyzed by Northern blots. AChE mRNA levels in stimulated fast muscles dropped to $10-20 \%$ of control after 1 week and became comparable to those in slow soleus muscles. The activity of the junctional $A_{12}$ AChE form in $35 \mathrm{~d}$ stimulated fast muscles decreased to $56 \%$ of control value, reaching that in the soleus muscle. Therefore, synaptic AChE itself depends on the muscle activation pattern. Complete inactivity after denervation also
\end{abstract}

decreased the AChE mRNA level in fast muscles to $<10 \%$ in 48 hr. In contrast, profuse fibrillations observed in noninnervated immature regenerating muscles maintain AChE mRNA levels at $80 \%$ of that in the innervated fast muscles. If protein synthesis was inhibited by cycloheximide, AChE mRNA levels in 3-d-old regenerating muscle, still containing myoblasts, increased approximately twofold. No significant increase after cycloheximide application was observed either in denervated mature fast muscles or in normal slow muscles. Low AChE mRNA levels observed in those muscles are probably not caused by decreased stability of AChE mRNA as demonstrated in myoblasts.

Key words: acetylcholinesterase; denervation; muscle; muscle stimulation; nerve-muscle interaction; nerve impulse pattern; neuromuscular junction; plasticity; regeneration; synapse
Skeletal muscle fibers are able to change their phenotype in response to altered functional demands (Pette and Staron, 1997). Many functional elements in fast muscle fibers can be transformed by chronic low-frequency stimulation, e.g., contractile proteins, the $\mathrm{Ca}^{2+}$-handling system, and enzymes of energy metabolism (Pette and Vrbovà, 1992). Therefore, fast muscles, stimulated by an impulse pattern similar to that in slow muscles, display several, although not necessarily all, characteristics of a slow soleus muscle (Westgaard and Lømo, 1988; Termin et al., 1989; Schiaffino et al.,1990; Pette and Vrbovà, 1994). Acetylcholinesterase (AChE; EC 3.1.1.7) activity in muscle fibers can also be changed by electrostimulation or disuse of muscles, which adds this enzyme to the list of proteins affected by the pattern of muscle activation (Dettbarn et al., 1985; Lømo et al., 1985; Sketelj and Črešnar, 1995; Sketelj et al., 1997).

AChE, which is responsible for fast hydrolysis of acetylcholine in the neuromuscular junction (NMJ) (Marnay and Nachmansohn, 1938; Eccles et al., 1942), is highly concentrated in the junctional basal lamina. It is present in a lower concentration throughout the length of muscle fibers (Sketelj, 1994). AChE displays a rich molecular polymorphism that encompasses globular and asymmetric molecular forms (Massoulié and Bon, 1982).

Received Oct. 9, 1997; revised Dec. 15, 1997; accepted Dec. 29, 1997.

This study was supported by a grant from the Ministry of Science and Technology of the Republic of Slovenia (J.S.) and Deutsche Forschungsgemeinschaft, Sonderforschungsbereich 156, TP/B3 (D.P.). The skillful technical assistance of Mr. Boris Pečenko and Mrs. Elmi Leisner is gratefully acknowledged. We thank Dr. M. Mihelin for help with EMG recording.

Correspondence should be addressed to Dr. Janez Sketelj, Institute of Pathophysiology, Zaloška 4, 1000 Ljubljana, Slovenia.

Copyright (C) 1998 Society for Neuroscience $0270-6474 / 98 / 181944-09 \$ 05.00 / 0$
The asymmetric molecular forms of AChE, bound to the junctional basal lamina, contribute most to the junctional AChE activity in mammalian muscles (Hall, 1973; Fernandez et al., 1984; Sketelj and Brzin, 1985; Inestrosa and Parelman, 1990; Rossi and Rotundo, 1996; Rotundo et al., 1997).

$\mathrm{AChE}$ regulation in predominantly fast rat muscles, such as extensor digitorum longus (EDL), is different from that in the slow soleus muscle (Bacou et al., 1982; Groswald and Dettbarn, 1983; Lai et al., 1986; Sketelj et al., 1992a). Most conspicuously, total AChE activity per unit of muscle weight, as well as activity of the globular molecular forms, is higher in fast than in slow muscles (Groswald and Dettbarn, 1983; Sketelj et al., 1992b), probably because of the much higher transcript level of the AChE catalytic subunit in fast muscles (Črešnar et al., 1994; Michel et al., 1994).

Some differences in $\mathrm{AChE}$ regulation may be attributable to intrinsic properties of the two types of muscles (Sketelj et al., 1991; Dolenc et al., 1994). However, because the patterns of neural activation of motor units in fast and slow rat muscles are very different (Navarrete and Vrbovà, 1983; Hennig and Lømo, 1985), we hypothesized that mRNA levels of AChE catalytic subunit and AChE synaptic activity in muscles depend on specific neural activation patterns. Indeed, the AChE mRNA level in fast muscles was found to decrease after 1 week of chronic lowfrequency stimulation and became comparable to that in the slow soleus muscle. The activity of the asymmetric AChE forms in the motor endplates of chronically stimulated fast muscles decreased too, revealing a dependence of functional AChE activity in the synapse itself on the muscle activation pattern. Low levels of AChE transcripts found in tonically activated or completely in- 
active muscles are probably not caused by the increased AChE mRNA degradation rate that is characteristic of early stages of muscle development.

\section{MATERIALS AND METHODS}

Animals. In accordance with national guidelines, the experiments on animals in Slovenia were approved by the Veterinary Administration of the Ministry for Agriculture, Forestry and Food, permit 326-07-258/95, and in Germany by the Regierungspräsidium Freiburg, authorization Az. 37/9185.815/733.

Experiments were performed on adult male Wistar rats. For surgical procedures, rats were anesthetized by a mixture of Ketalar (Parke-Davis, Vienna, Austria; $60 \mathrm{mg} / \mathrm{kg}$ ), Rompun (Bayer, Leverkusen, Germany; 8 $\mathrm{mg} / \mathrm{kg}$ ), and atropine (Belupo, Koprivnica, Croatia; $0.6 \mathrm{mg} / \mathrm{kg}$ ), or by sodium pentobarbital (Werfft-Chemie, Wels, Austria; $55 \mathrm{mg} / \mathrm{kg}$ ), injected intraperitoneally. The animals were exsanguinated under ether anesthesia.

Low-frequency stimulation of EDL and tibialis anterior (TA) muscles. Stainless steel electrodes were implanted under anesthesia on each side of the peroneal nerve of the left hindlimb (Simoneau and Pette, 1988). Stimulation was performed using a battery-operated, portable stimulator (Tyler and Wright, 1980). Square wave stimuli $(10 \mathrm{~Hz}$, single pulse duration $30 \mathrm{msec}$ ) were applied continuously for $10 \mathrm{hr}$ per day for either 7,25 , or $35 \mathrm{~d}$. The amplitude of stimulation was adjusted daily so that maximum contraction of the stimulated muscle group could be palpated and stimulation did not cause apparent discomfort to the animals.

Muscle denervation. The sciatic nerve in one leg was exposed and transected in a midthigh region. A piece of the nerve was excised to prevent reinnervation.

Noninnervated regenerating muscle. One leg was denervated as described above, and the EDL muscle was exposed in that leg. The muscle was thereafter injected with the myotoxic local anesthetic Marcaine (0.5\% bupivacaine; Astra, Södertälje, Sweden) as described (HallCraggs, 1974). The wound was closed, the animals were left to recover, and the muscles were allowed to regenerate for 3 or $8 \mathrm{~d}$.

Cycloheximide treatment. Rats were injected intraperitoneally with 20 $\mathrm{mg} / \mathrm{kg}$ of cycloheximide in PBS. Four hours later, they were given another $10 \mathrm{mg} / \mathrm{kg}$ of cycloheximide. Controls were injected with saline. The animals were killed $8 \mathrm{hr}$ after the first injection, and muscles to be used for further analysis were immediately isolated and frozen.

Velocity sedimentation analysis of AChE. The EDL and soleus muscles of both hindlimbs were isolated (muscles from the nontreated leg served as controls). Regions containing NMJs (junctional regions) were separated from regions without them (extrajunctional regions) (Koenig and Rieger, 1981; Sketelj et al., 1993). The samples were weighed, frozen in liquid nitrogen, and kept at $-80^{\circ} \mathrm{C}$ until they were analyzed. Frozen muscle samples were crushed and pulverized in a mortar chilled in liquid nitrogen and then immediately homogenized. An ice-cold high-saltdetergent medium with a set of protease inhibitors was used to extract AChE, which was then subjected to velocity sedimentation analysis in 5-20\% linear sucrose gradients as described (Sketelj et al., 1993). The activity pertaining to an individual molecular form of AChE was calculated by measuring the area under its peak of activity in the velocity sedimentation pattern, using our own computer program (Ribarič et al., 1996).

Northern blot analysis. EDL, TA, diaphragm, or soleus muscles were isolated rapidly under antiseptic conditions and frozen immediately in liquid nitrogen. Frozen muscles were pulverized in a mortar chilled by liquid nitrogen and briefly homogenized in denaturing solution by an Ultra-Turrax homogenizer. Total RNA was isolated by a slightly modified single-step procedure (Chomczynski and Sacchi, 1987), subjected to electrophoresis in $1.2 \%$ denaturing formaldehyde-agarose gel ( $30-50 \mu \mathrm{g}$ of RNA per lane), and transferred to nylon membranes by capillary blotting (Hybond N, Amersham, Arlington Heights, IL). Specific DNA probe corresponding to a fragment of the cDNA of the rat AChE catalytic subunit (common catalytic domain, nucleotides 920-1683; a gift by Dr. C. Legay and Dr. J. Massoulié, Paris, France) was used for hybridization. Random prime kit components (Boehringer Mannheim, Mannheim, Germany) were used for labeling the probe with $\alpha^{32} \mathrm{P}$ dCTP (DuPont de Nemours, Brussels, Belgium). A specific synthetic oligonucleotide complementary to the $3^{\prime}$ end of the probe (Ransom Hill Bioscience, Ramona, CA) was used as the primer instead of random oligonucleotides. The membranes were prehybridized for $1 \mathrm{hr}$ at $42^{\circ} \mathrm{C}$ in a buffer solution containing $5 \times$ SSPE, $50 \%$ formamide, $5 \times$ Denhardt's solution, $0.5 \%$ SDS, and $20 \mu \mathrm{g} / \mathrm{ml}$ salmon sperm DNA (Sigma, St. Louis, MO). Hybridization was performed at $42^{\circ} \mathrm{C}$ overnight in the same solution with the addition of the radioactive probe to $\sim 10^{6} \mathrm{cpm} / \mathrm{ml}$. The blots were washed in $2 \times$ SSPE at room temperature, then twice for 15 $\min$ in $2 \times$ SSPE and $0.1 \%$ SDS at $42^{\circ} \mathrm{C}$, then for $30 \mathrm{~min}$ in $1 \times$ SSPE and $0.1 \%$ SDS at $42^{\circ} \mathrm{C}$, and finally two times for $15 \mathrm{~min}$ in $0.1 \times$ SSPE and $0.1 \%$ SDS at room temperature. The membranes were exposed to $\mathrm{x}$-ray films using intensifying screen for 1-4 d. The AChE probe was then stripped off the membranes, and they were rehybridized by radioactive $\beta$-actin probe as described above. The autoradiograms were quantified densitometrically using MCID M4 image analyzer by Imaging Research, and the values for AChE mRNA were normalized in regard to the intensity of the corresponding $\beta$-actin signal.

$E M G$ recording. The rats were anesthetized as described and kept on a warm blanket to prevent hypothermia. Skin and muscle fascia on the frontal side of the calf were incised, and the EDL muscle (control, denervated, or regenerating) was carefully exposed. A disposable concentric needle electrode (No. 53155, recording area $0.07 \mathrm{~mm}^{2}$ ) was inserted into the muscle at several sites consecutively. Spontaneous electromyographic activity followed and was recorded several times during the next 10-30 min by a Mystro electromyograph (Medelec, Old Woking, UK). The frequency bandwidth used was $0.2-2.0 \mathrm{kHz}$.

\section{RESULTS}

\section{Levels of AChE mRNA and molecular forms of AChE in different rat muscles}

Gene transcript levels of AChE catalytic subunit were determined in several rat muscles differing in regard to their speed of contraction, fiber type composition, and expression of myosin heavy chain (MHC) isoforms. AChE mRNA levels were found to be higher in fast muscles such as EDL and TA than in slower ones such as the diaphragm and soleus (Fig. $1 B$ ). We used densitometric evaluation and assigned a value of 100 to the mRNA level in the EDL muscle, and the average mRNA levels in the TA were $\sim 70$, in the diaphragm $\sim 50$, and in the soleus $\sim 15$ (Fig. 1C). The relative levels of $\mathrm{AChE}$ mRNA in the examined muscles were roughly proportional to activities of the monomeric $4 \mathrm{~S}$ molecular form of $\mathrm{AChE}$ in the extrajunctional regions of these muscles (Fig. 1 $A, C$ ).

The asymmetric $\mathrm{A}_{12}$ molecular forms of $\mathrm{AChE}$ are highly concentrated in NMJs of rat muscles and contribute most of the junctional AChE activity (Hall, 1973). We analyzed the patterns of molecular forms of $\mathrm{AChE}$ separately in the muscle region containing all of the NMJs (junctional region) and in muscle regions without NMJs (extrajunctional regions). By deducting the specific activity of the $A_{12}$ AChE form in the extrajunctional region from that in the junctional region, the activity of the synaptic $\mathrm{A}_{12}$ form proper in the junctional region was calculated, both in the fast EDL muscle and in the slow soleus muscle. The number of muscle fibers (and therefore, of motor endplates) in the two muscles was determined in stained histological crosssections (EDL, $3120 \pm 20$ fibers; soleus, $1790 \pm 60$ fibers; mean \pm $\mathrm{SE} ; n=3$ ), and $\mathrm{A}_{12} \mathrm{AChE}$ activity per NMJ in the two muscles was calculated. The activity of the $\mathrm{A}_{12} \mathrm{AChE}$ per endplate in the soleus muscles was $\sim 60 \%$ of that in the EDL $(4.5 \pm 0.5 \mathrm{fmol}$ $\mathrm{ACh} / \mathrm{min}$ vs $7.3 \pm 0.3 \mathrm{fmol} \mathrm{ACh} / \mathrm{min}$; mean $\pm \mathrm{SD} ; n=4)$; the difference was statistically significant $(p<0.01)$.

\section{The effect of chronic low-frequency stimulation on AChE mRNA levels and its synaptic activity in fast muscles}

In rats, fast muscles are normally activated by rare, short-lasting high-frequency bursts of nerve impulses (Navarrete and Vrbovà, 1983; Hennig and Lømo, 1985). Chronic low-frequency electrical stimulation of fast EDL and TA muscles via their nerves subjected the two muscles to an activation pattern similar to that in 

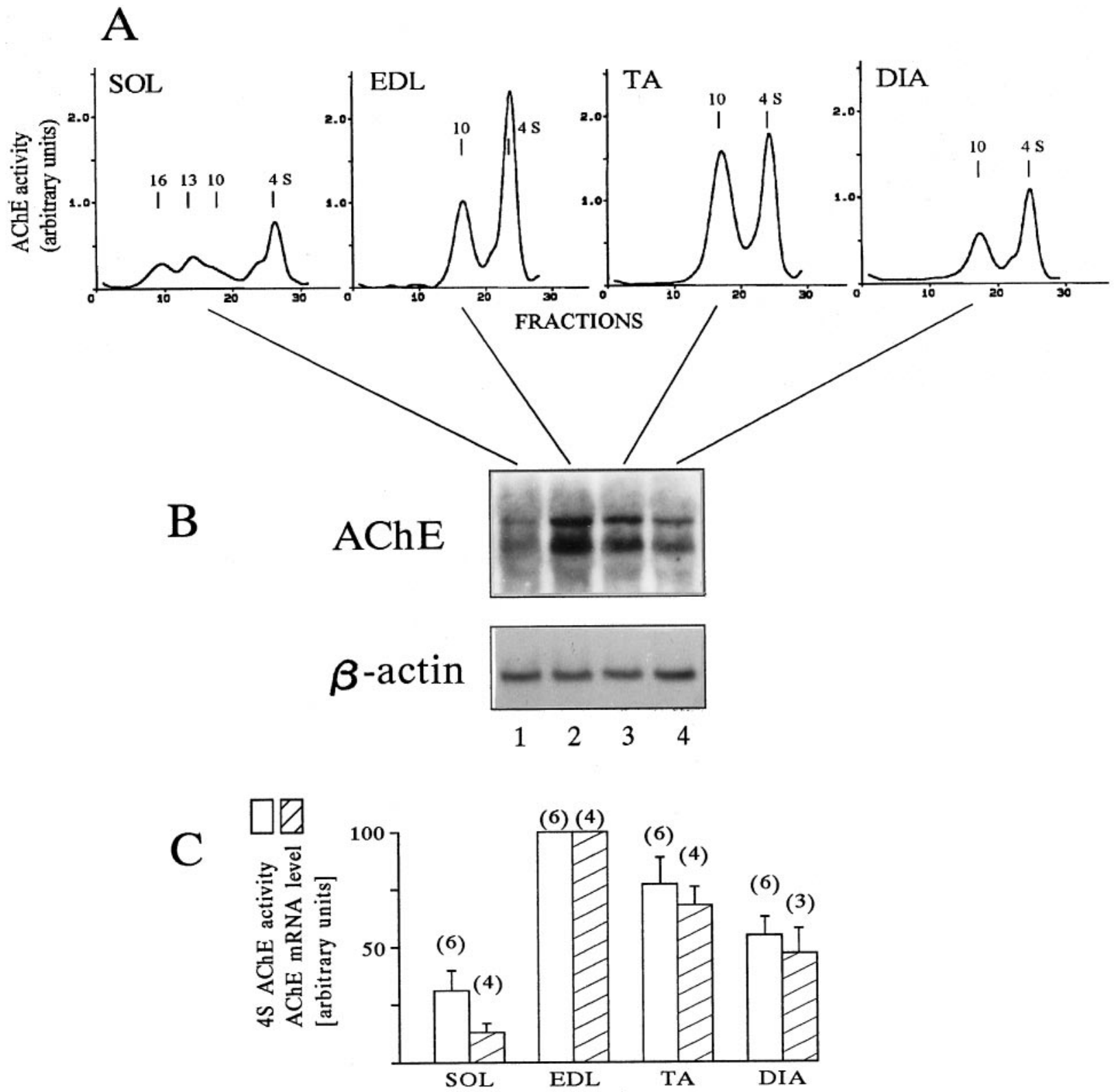

Figure 1. AChE expression in four different rat muscles: soleus (SOL, lane 1), extensor digitorum longus (EDL, lane 2), tibialis anterior (TA, lane 3), and the diaphragm (DIA, lane 4). A, Velocity sedimentation patterns of AChE molecular forms, identified by their sedimentation coefficients, in the extrajunctional muscle regions; AChE activity is expressed in arbitrary units per unit of wet weight. $B$, Northern blot analysis of AChE mRNA levels in muscles. $\beta$-actin mRNA was used to control uniformity of sample loading. $C$, Relative levels of the $4 \mathrm{~S}$ AChE form activity (blank bars) and AChE mRNA (hatched bars) in rat muscles (mean $+\mathrm{SE}$; the number of determinations is given in parentheses).

the slow soleus muscle. We found that after only 1 week $\mathrm{AChE}$ mRNA levels in both stimulated fast muscles fell to low values comparable to those in the soleus muscle ( $\sim 10-20 \%$ of the AChE mRNA levels in control fast muscles). Low levels of AChE mRNA in chronically stimulated EDL muscle also persisted after $25 \mathrm{~d}$ of stimulation (Fig. 2).

In addition, the patterns of $\mathrm{AChE}$ molecular forms in the junctional regions of $35 \mathrm{~d}$ stimulated and control EDL muscles were analyzed (Fig. $3 A$ ). Specific activity of the monomeric $\mathrm{G}_{1}$ form was heavily reduced in the stimulated muscles. Activity of the junctional $\mathrm{A}_{12} \mathrm{AChE}$ form calculated per NMJ in the stimulated EDL was only $\sim 56 \%$ of that in the control EDL muscle $(p<0.05)$ and was about the same as that in the NMJs of normal soleus muscles (Fig. 3B).
The effect of muscle inactivity caused by denervation on the levels of AChE mRNA in fast muscles

We focused our attention on an early period after denervation that was characterized by complete muscle inactivity. Northern blot analysis of denervated EDL muscles revealed that mRNA levels of AChE started to decrease during the first $24 \mathrm{hr}$ after denervation (Fig. 4A,B). At that time, AChE mRNA levels were already reduced to $\sim 30 \%$ of control levels. AChE mRNA levels in the denervated EDL muscles were further reduced to just a small percentage of control levels after $48 \mathrm{hr}$ of inactivity.

AChE mRNA levels also were examined in noninnervated muscles that regenerated after injury. We let muscle regeneration take place in the absence of innervation to be able to compare denervated immature regenerating muscles with denervated ma- 

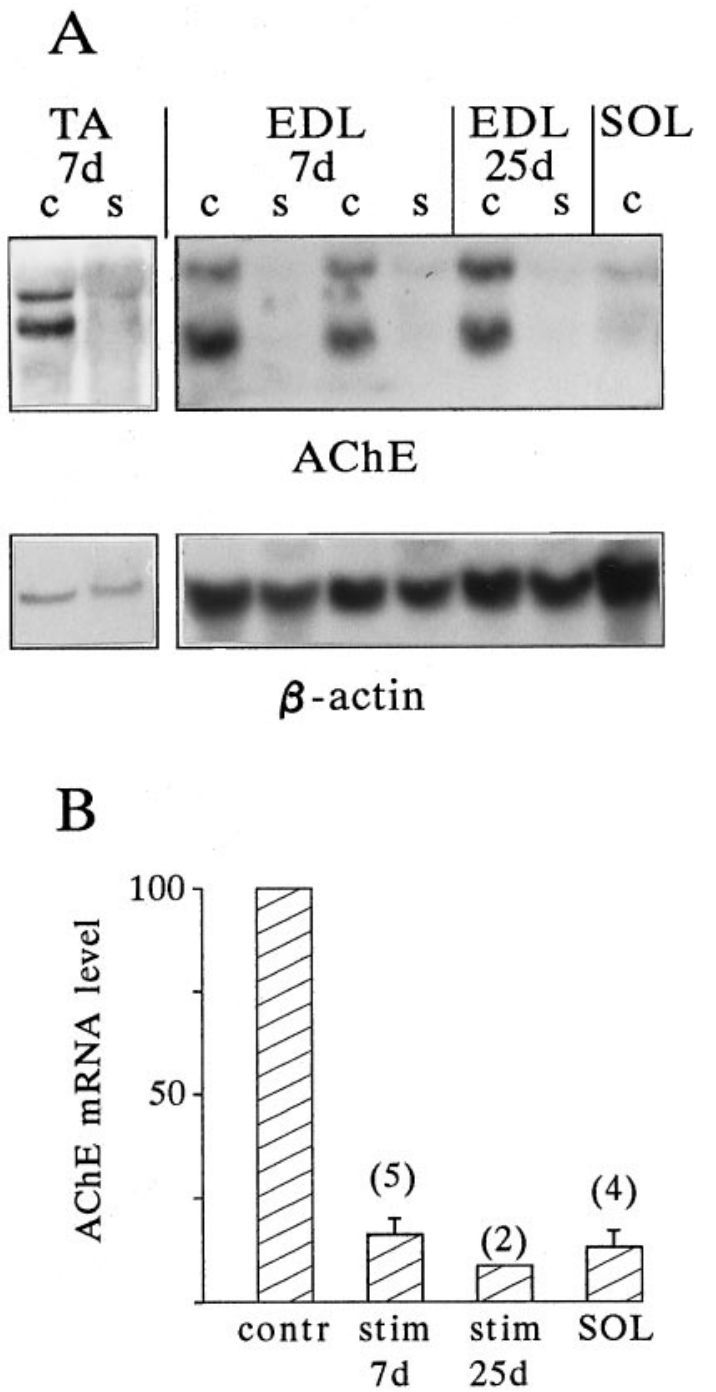

Figure 2. The effect of chronic low-frequency stimulation on AChE mRNA levels in fast muscles tibialis anterior $(T A)$ and extensor digitorum longus $(E D L) . A$, Northern blot analysis of control $(c)$ and stimulated $(s)$ muscles, stimulation lasting $7 \mathrm{~d}(7 d)$ or $25 \mathrm{~d}(25 d)$. Normal soleus muscle $(S O L)$ is included for comparison; $\beta$-actin mRNA was used to control uniformity of sample loading. $B$, Histogram of relative levels of AChE mRNA in control (contr) and stimulated (stim) EDL muscles in comparison to soleus $(S O L)$ muscle (mean $+\mathrm{SE}$ of several determinations; the number of determinations is given in parentheses).

ture muscles. In contrast to mature $8 \mathrm{~d}$ denervated muscles, AChE mRNA levels in noninnervated 8-d-old regenerating fast muscles were fairly high, i.e., $\sim 80 \%$ of those in control mature innervated muscles (Fig. 4).

Electromyographic recording of spontaneous muscle activity in denervated mature and regenerating muscles was performed to examine the hypothesis that possible differences in spontaneous activity might be responsible for different AChE mRNA levels in mature versus immature denervated muscles (Fig. 5). In denervated mature muscles, we were able to record spontaneous fibrillations at 10 of 18 recording sites in three $8 \mathrm{~d}$ denervated EDL muscles, using standard concentric needle electrodes. Action potentials originating from one or a few muscle fibers were observed at recording sites with activity. Individual muscle fibers fibrillated with frequencies ranging from $\sim 0.5$ to $5 \mathrm{~Hz}$. In the noninnervated
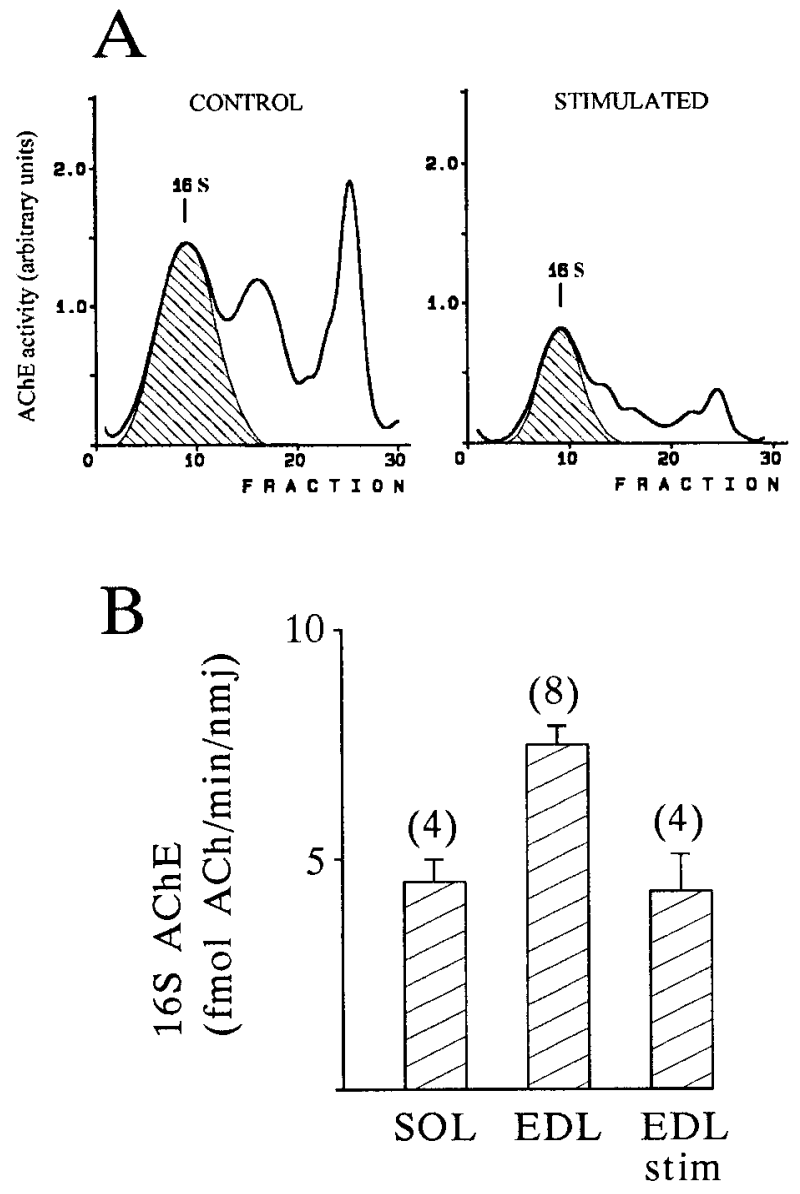

Figure 3. The effect of chronic low-frequency stimulation on the junctional $16 \mathrm{~S}\left(\mathrm{~A}_{12}\right) \mathrm{AChE}$ form in fast extensor digitorum longus $(E D L)$ muscles. $A$, Velocity sedimentation pattern of AChE molecular forms in the junctional region of control and $35 \mathrm{~d}$ stimulated EDL muscles; the peak corresponding to the $16 \mathrm{~S}$ form is hatched. AChE activity is expressed in arbitrary units per neuromuscular junction. $B$, Activities of the $16 \mathrm{~S}$ AChE form per neuromuscular junction in soleus $(S O L)$ muscles, control EDL muscles $(E D L)$, and $35 \mathrm{~d}$ stimulated EDL muscles $(E D L$ stim) (mean + SE; the number of determinations is given in parentheses).

regenerating muscles, however, profuse spontaneous fibrillatory activity could always be recorded at each impalement by the same EMG electrode. The number of active fibers within the reach of the electrode was too great to allow more detailed analysis of the firing rate of individual muscle fibers.

\section{The effect of cycloheximide treatment on AChE mRNA levels in very immature regenerating muscle and various mature muscles}

Inhibition of protein synthesis in myoblasts in vitro by cycloheximide for $6 \mathrm{hr}$ caused a great increase of AChE mRNA levels in these cells, probably because of inhibited synthesis of short-lived proteins responsible for the fast degradation rate of AChE mRNA in myoblasts (Fuentes and Taylor, 1993). We found that the level of AChE mRNA in 3-d-old regenerating EDL muscles was $<50 \%$ of that in more mature 8 -d-old regenerating muscles (Fig. 6). In accordance with the results obtained in vitro, we found an 1.8-fold increase of AChE mRNA levels in early regenerating EDL muscles $8 \mathrm{hr}$ after we treated the rats with a high dose of cycloheximide. It is possible that low AChE mRNA levels observed in either inactive muscles or tonically activated muscles are caused by an accelerated AChE mRNA degradation rate, as 
A

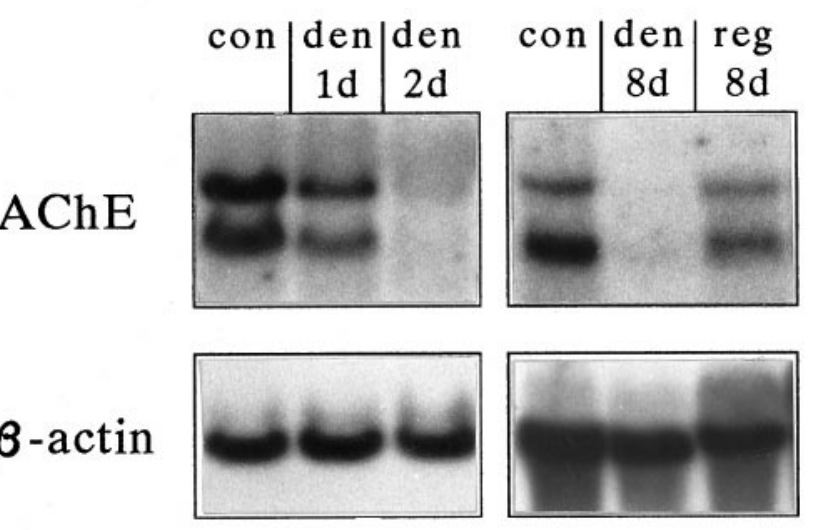

B

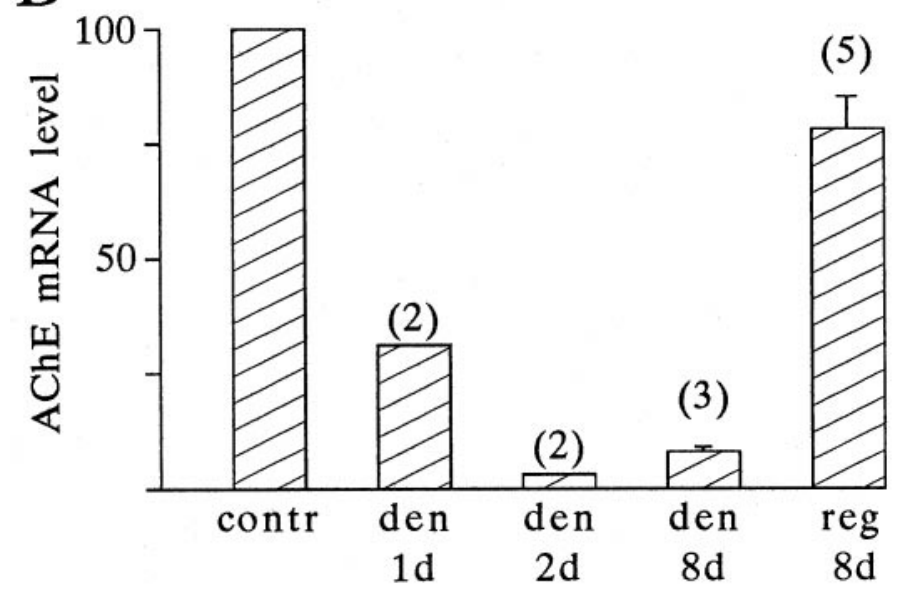

Figure 4. The effect of denervation on AChE mRNA levels in mature and regenerating EDL muscles. $A$, Northern blot analysis of AChE mRNA levels in control EDL (con), EDL denervated (den) for $24 \mathrm{hr}(1 d)$, $48 \mathrm{hr}(2 d)$, or $8 \mathrm{~d}(8 d)$, and in noninnervated 8-d-old regenerating EDL muscle $(r e g 8 d)$. $\beta$-Actin mRNA was used to control uniformity of sample loading. $B$, Histogram of relative AChE mRNA levels in control (contr) and different kinds of denervated EDL muscles (mean $+\mathrm{SE}$; the number of determinations is given in parentheses).

in immature muscle cells. However, in the rats treated with a high dose of cycloheximide, no major increase of AChE mRNA levels could be detected after $8 \mathrm{hr}$ of cycloheximide treatment either in denervated fast muscles or in normal innervated slow soleus muscles (Fig. 6).

\section{DISCUSSION}

\section{AChE mRNA levels in rat muscles depend on the muscle activation pattern}

$\mathrm{AChE}$ expression was examined in four rat muscles displaying different patterns of MHC isoforms: EDL: 60-65\% MHCIIb, 25-35\% MHCIId/x, 10-12\% MHCIIa, 1\% MHCI; TA: 60-77\% MHCIIb, 19-25\% MHCIId/x, 4-14\% MHCIIa, 0-4\% MHCI; diaphragm: $1 \%$ MHCIIb, 53\% MHCIId/x, 32\% MHCIIa, 14\% MHCI; and soleus: 0\% MHCIIb, 0\% MHCIId/x, 10-20\% MHCIIa, 80-90\% MHCI (Bär and Pette, 1988; Kirschbaum et al., 1990; Pette and Staron, 1990; Snoj-Cvetko et al., 1996; Sketelj et al., 1997). We found that high cumulative percentages of the fastest $\mathrm{MHC}$ isoforms $\mathrm{MHCIIb}$ and $\mathrm{IId} / \mathrm{x}$ and low percentages of the isoform MHCIIa and slow isoform MHCI were associated with high levels of AChE transcripts in a muscle, and vice versa.
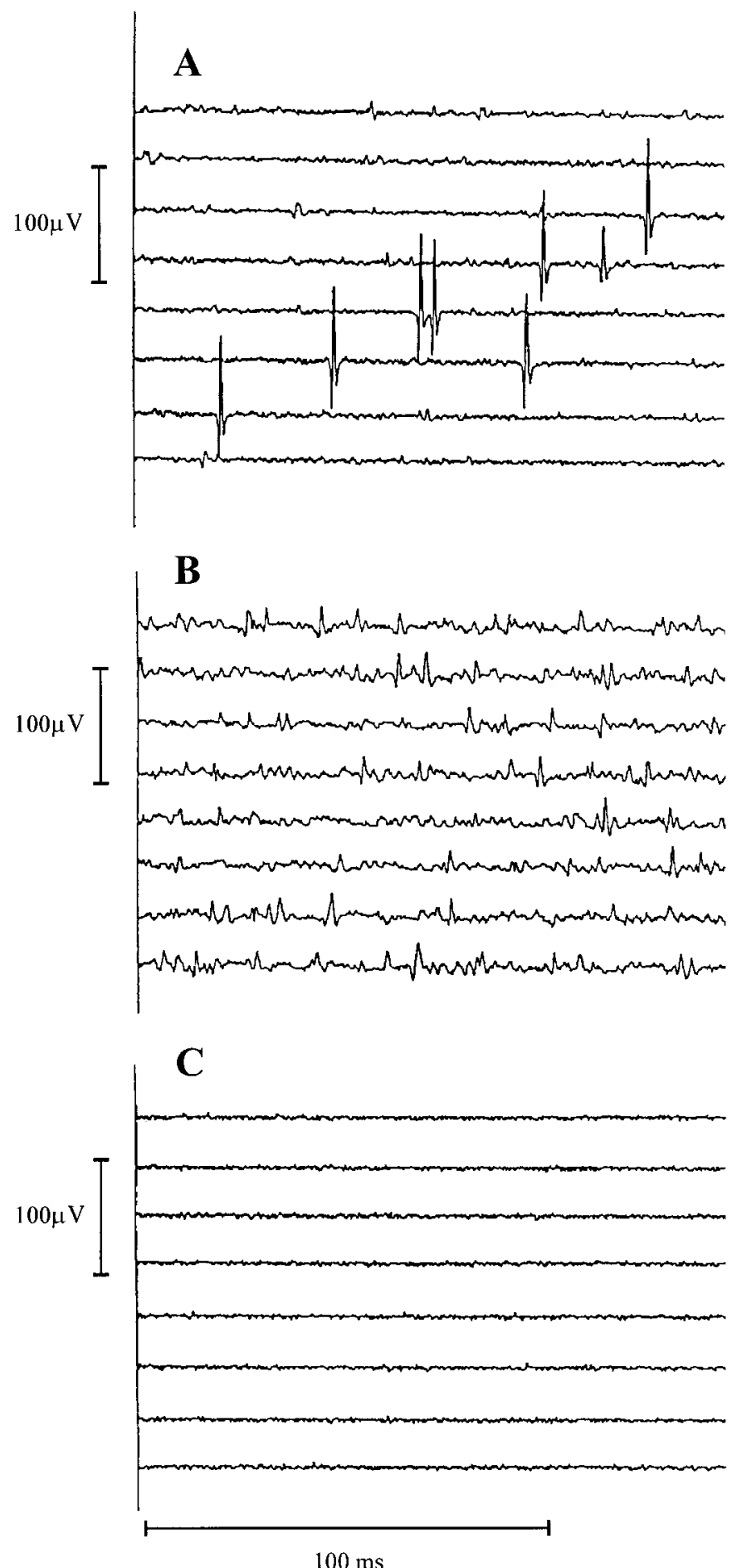

Figure 5. Representative examples of electromyographic recordings of spontaneous electrical activity in denervated EDL muscles. $A$, Three muscle fibers firing in the neighborhood of the electrode in an $8 \mathrm{~d}$ denervated mature EDL muscle. $B$, Profuse fibrillatory activity in an 8-d-old noninnervated regenerating EDL muscle. $C$, Electrical silence in a normal EDL muscle, showing the level of noise.

Activity of the monomeric $4 \mathrm{~S}$ AChE form $\left(\mathrm{G}_{1}\right)$, reflecting the concentration of the basic catalytic subunit of AChE, roughly parallelled the levels of AChE mRNA in the examined muscles. Because the most important factor determining the MHC profile of a muscle, although not the only one, is a specific pattern of 
A

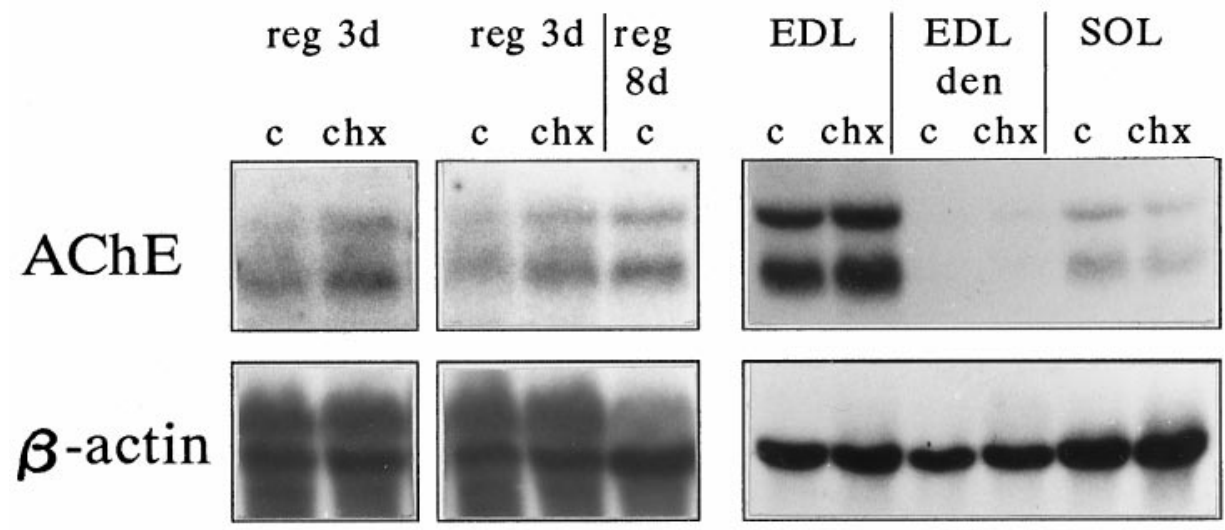

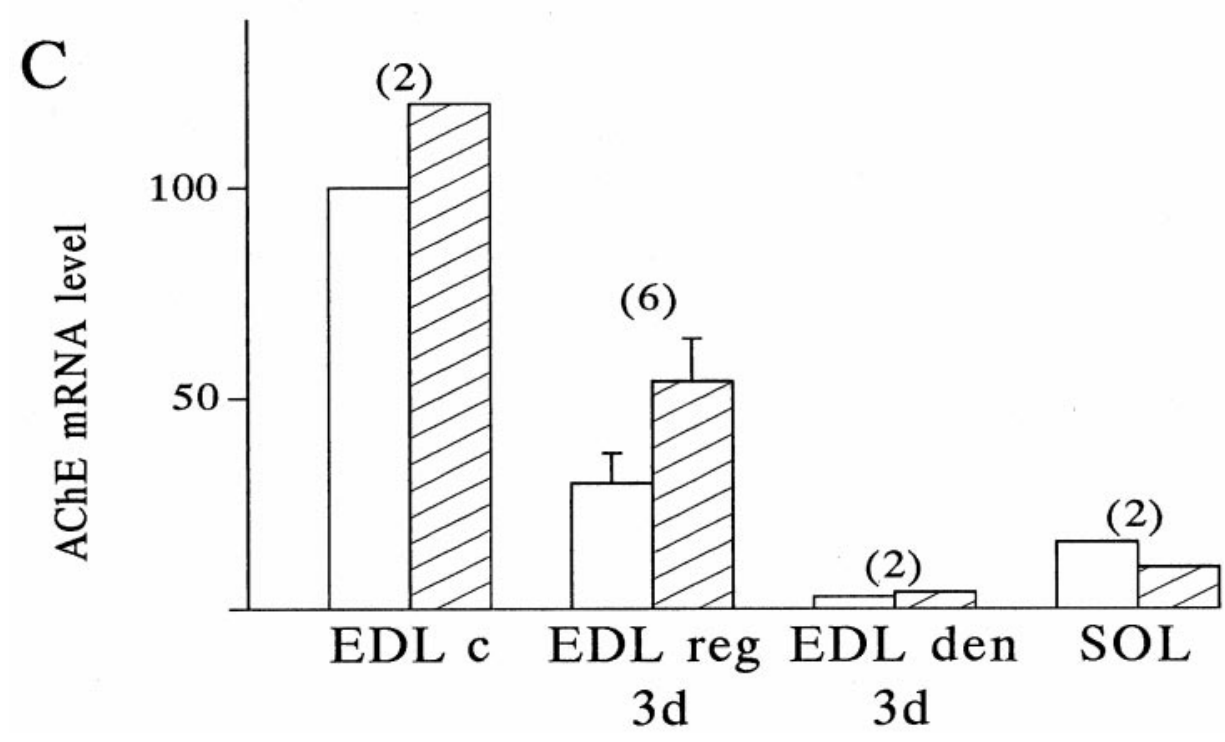

Figure 6. The effect of cycloheximide on AChE mRNA levels in different muscles $8 \mathrm{hr}$ after the rats received the drug. $A$, Northern blot analysis of AChE mRNA levels in 3-d-old regenerating EDL muscles (reg $3 d$ ) in control (c) and cycloheximide-treated ( $\operatorname{ch} x)$ rats, with an 8-d-old control regenerating muscle (reg $8 d$ ) shown for comparison. $B$, Northern blot analysis of AChE mRNA levels in normal EDL, $3 \mathrm{~d}$ denervated mature EDL (EDL den) and normal soleus $(S O L)$ muscles from control $(c)$ or cycloheximide-treated $(\operatorname{ch} x)$ rats. $\beta$-actin mRNA was used for control of uniformity of sample loading. $C$, Relative levels of AChE mRNA in control EDL (EDL $c)$, 3-d-old noninnervated regenerating EDL (EDL reg $3 d$ ), $3 \mathrm{~d}$ denervated mature EDL (EDL den $3 d$ ), and normal soleus (SOL) muscles in control (blank bars) or cycloheximide-treated animals (hatched bars) (mean $+\mathrm{SE}$; the number of determinations is given in parentheses). neural activation of muscle fibers (Pette and Staron, 1997), the above results indirectly support the hypothesis that the $\mathrm{AChE}$ mRNA level in muscles also depends on the neural activation pattern. However, although the MHC profiles of EDL and TA muscles are fairly similar, the AChE transcript level and activity of the $\mathrm{G}_{1}$ AChE form were consistently higher, whereas the activity of the $\mathrm{G}_{4}$ form was lower in the EDL compared with the TA. The latter observation indicates that this may be attributable to a greater work load imposed on the TA than on the EDL muscle (Fernandez and Hodges-Savola, 1992; Gisiger et al., 1994; Boudreaularviere et al., 1997). Some mechanisms seem to modify AChE expression to a certain extent independently of MHC regulation.

Fast motor units in rat muscles such as EDL are activated phasically, with short high-frequency bursts interspersed with long periods of inactivity (Fischbach and Robbins, 1969; Navarette and Vrbovà, 1983; Hennig and Lømo, 1985). We demonstrated that by imposing a chronic low-frequency stimulation, which roughly mimics the tonic activation pattern in slow muscle fibers, on fast muscles such as EDL or TA, high levels of AChE mRNA in these muscles became reduced to a low level characteristic of the soleus muscle after 1 week, and they persisted for at least a few weeks thereafter. Conversely, AChE activity and the transcript levels in the soleus muscle were reported to increase after its disuse (Dettbarn et al., 1985; Sketelj and Črešnar, 1995), which changed its pattern of activation from tonic to phasic and greatly reduced the aggregate number of nerve impulses per day (Fischbach and Robbins, 1969). Therefore, the AChE mRNA level in a rat muscle depends on specific neural activation patterns: rare phasic bursts of high-frequency activity enhance and continuous tonic low-frequency muscle activation reduces $\mathrm{AChE}$ mRNA levels.

\section{Activity of the junctional asymmetric AChE forms is affected by the pattern of muscle activation}

We found earlier that activity of the globular molecular forms of $\mathrm{AChE}$ in the extrajunctional muscle regions decreased after continuous muscle stimulation (Sketelj et al., 1997). In addition, we show here that activity of the functionally most important part of muscle AChE, i.e., activity of the multimeric asymmetric AChE forms in the neuromuscular junction itself, parallels the available amount of catalytic subunits and the level of AChE mRNA: activity of the synaptic $\mathrm{A}_{12} \mathrm{AChE}$ form in control EDL was nearly two times higher than in the stimulated EDL or in the normal soleus muscles. Accordingly, transgenically overexpressed AChE in embryonic muscles caused an increase in the size of their 
NMJs (Shapira et al., 1994). However, the amount of $\mathrm{A}_{12} \mathrm{AChE}$ forms assembled from the catalytic subunits and the noncatalytic tail subunit is also determined by the expression of the collagenlike tail subunit (collagen Q) (Krejci et al., 1991; Duval et al., 1992; Bon and Massoulié, 1997; Krejci et al., 1997). At present, therefore, it is not possible to decide whether changes in expression of either catalytic or tail subunits, or both, are responsible for the observed changes in junctional $\mathrm{A}_{12} \mathrm{AChE}$ activity in chronically active muscles. Our data agree well with earlier indirect estimations of junctional AChE activity in slow and fast rat muscles using electrophysiological experiments (Magazanik et al., 1984). Higher junctional AChE activity in fast muscles, as compared with slow ones, may be an advantage when very rapid acetylcholine hydrolysis is required for transmission of nerve impulses at very high frequencies in fast muscles.

The idea that NMJ development is regulated by "trophic" factors released by the nerve ending has gained new support recently (Bowe and Fallon, 1995). Thus, expression of acetylcholine receptor in the subjunctional nuclei might be enhanced by calcitonin gene-related peptide (CGRP) (Fontaine et al., 1986; New and Mudge, 1986) and acetylcholine receptor-inducing activity (ARIA)-neuregulin (Harris et al., 1988; Falls et al., 1993; Chu et al., 1995). AChE transcripts are approximately 10 times more concentrated under the motor endplate than elsewhere in muscle fibers in different vertebrate species (Jasmin et al., 1993; Michel et al., 1994; Legay et al., 1995). Different sensitivity of AChE transcript levels to either denervation or tetrodotoxin paralysis of rat muscles suggested that trophic factors also regulated AChE expression in subjunctional nuclei (Michel et al., 1994). Indeed, CGRP had an innervation-like effect on the junctional $\mathrm{G}_{4} \mathrm{AChE}$ form in rat muscles (Hodges-Savola and Fernandez, 1995). It increased AChE mRNA levels in cultured chick muscles approximately threefold (Choi et al., 1996), but ARIAneuregulin had no effect (Pun and Tsim, 1995). In addition to this, our results suggest that junctional muscle nuclei, like the extrajunctional ones, still possess the ability to respond to different neural stimulation patterns as far as the regulation of junctional AChE is concerned.

\section{Either muscle inactivity or continuous muscle activation decreases AChE expression in muscles}

It has been shown before that the levels of AChE mRNA become very low in 5 to 10 d denervated rat muscles (Črešnar et al., 1994; Michel et al., 1994). In light of the present results, it was not clear whether this was attributable to muscle inactivity or chronic spontaneous low-frequency activity, called fibrillations, which appear in denervated rat muscles $\sim 2-3$ d after denervation (Hník and Škorpil, 1962; Salafski et al., 1968). We therefore examined the AChE mRNA level in the denervated EDL muscle before it starts fibrillating. The immediate decrease of AChE mRNA indicates that muscle inactivity itself is primarily responsible. Fibrillatory activity that appears later is insufficient to maintain the AChE mRNA levels, just as it is unable to prevent the extrajunctional appearance of acetylcholine receptors in denervated muscle fibers (Fambrough, 1970; Purves and Sakmann, 1974). Namely, periods of fibrillatory activity in individual denervated rat muscle fibers last on average $<1$ day and are interspersed with 2- to 3-d-long periods of electromechanical inactivity (Purves and Sakmann, 1974).

However, immature noninnervated rat muscle fibers express fairly high AChE activity either in culture or during regeneration in vivo (Sugiyama, 1977; Sketelj et al., 1987). We showed here that high AChE activity in noninnervated regenerating EDL muscles was caused by fairly high levels of AChE mRNA ( $~ 80 \%$ of control fast muscles). Because profuse spontaneous fibrillatory activity was recorded by EMG at each impalement of regenerating EDL muscles, it seems that spontaneous fibrillatory activity in noninnervated immature muscle fibers is sufficiently intense to sustain high AChE mRNA levels yet not too persistent to suppress it. Accordingly, a dramatic increase of AChE activity occurs in cultured rat myotubes after the onset of fibrillations but can be prevented if fibrillations are blocked by tetrodotoxin (Brockman et al., 1984; De La Porte et al., 1984; Rubin et al., 1985).

Regarding the mechanisms of AChE mRNA level dependence on muscle activation pattern, it is surprising that both inactivity and continuous muscle activation should have similar suppressive effects on AChE transcript levels. Either a decreased transcription rate or an enhanced mRNA degradation rate might be responsible for these effects. It has been shown that increased $\mathrm{AChE}$ expression after fusion of myoblasts into myotubes is attributable to a decrease of the AChE mRNA degradation rate, whereas its transcription rate does not change appreciably (Fuentes and Taylor, 1993). When cultured myoblasts were treated by the protein synthesis inhibitor cycloheximide, a prompt increase of AChE mRNA levels was noted. This "superinduction" was thought to be attributable to the suppressed synthesis of proteins responsible for destabilization of AChE mRNA (Fuentes and Taylor, 1993). We treated the rats with a dose of cycloheximide 10 -fold higher than that which produced $80 \%$ inhibition of protein synthesis (Dupret et al., 1986). Accordingly, $8 \mathrm{hr}$ later AChE mRNA levels in the early regenerating muscles, still containing myoblasts (Carlson, 1976; Hansen-Smith and Carlson, 1979), became approximately twofold higher than in the untreated controls. However, after we applied the same dose of cycloheximide, we could find no substantial increase of AChE mRNA levels either in normal slow soleus muscles or in denervated fast EDL muscles. This argues against the possibility that either denervated fast muscles or tonically activated muscles display low levels of AChE mRNA because of relapsing to a very immature state in which an increased AChE mRNA degradation rate would reduce its steady-state levels. Accordingly, immature myotubes in vitro, although noninnervated, have already achieved AChE mRNA stabilization (Fuentes and Taylor, 1993). These results favor the view that AChE mRNA stabilization is a very early, and possibly irreversible, event during muscle cell differentiation. We propose that at later stages, regulation of $\mathrm{AChE}$ mRNA levels by muscle activation pattern is based on regulation of the AChE mRNA transcription rate. Our results support this assumption, although they do not prove it.

\section{REFERENCES}

Bacou F, Vigneron P, Massoulié J (1982) Acetylcholinesterase forms in fast and slow rabbit muscle. Nature 296:661-664.

Bär A, Pette D (1988) Three fast myosin heavy chains in adult rat skeletal muscle. FEBS Lett 235:153-155.

Bon S, Massoulié J (1997) Quaternary associations of acetylcholinesterase. J Biol Chem 272:3007-3015.

Boudreaularviere C, Gisiger V, Michel RN, Hubatsch DA, Jasmin BJ (1997) Fast and slow skeletal muscles express a common basic profile of acetylcholinesterase molecular forms. Am J Physiol 41:C68-C76.

Bowe MA, Fallon JR (1995) The role of agrin in synapse formation. Annu Rev Neurosci 18:443-462.

Brockman SM, Younkin LH, Younkin SG (1984) The effect of spontaneous electromechanical activity on the metabolism of acetylcholinesterase in cultured embryonic rat myotubes. J Neurosci 4:131-140.

Carlson BM (1976) A quantitative study of muscle fiber survival and 
regeneration in normal, predenervated, and Marcaine-treated free muscle grafts in the rat. Exp Neurol 52:421-432.

Choi RCY, Leung PWY, Dong TTX, Wan DCC, Tsim KWK (1996) Calcitonin gene-related peptide increases the expression of acetylcholinesterase in cultured chick myotubes. Neurosci Lett 217:165-168.

Chomczynski P, Sacchi N (1987) Single-step method of RNA isolation by acid guanidinium thiocyanate-phenol-chloroform extraction. Anal Biochem 162:156-159.

Chu GC, Moscoso LM, Sliwkowski MX, Merlie JP (1995) Regulation of the acetylcholine receptor $\epsilon$ subunit gene by recombinant ARIA: an in vitro model for transynaptic gene regulation. Neuron 14:329-339.

Crešnar B, Crne-Finderle N, Breskvar K, Sketelj J (1994) Neural regulation of muscle acetylcholinesterase is exerted on the level of its mRNA. J Neurosci Res 38:294-299.

De La Porte S, Vigny M, Massoulié J, Koenig J (1984) Action of veratridine on acetylcholinesterase in cultures of rat muscle cells. Dev Biol 106:450-456.

Dettbarn W-D, Groswald D, Gupta RC, Misulis KE (1985) Use and disuse and the control of acetylcholinesterase activity in fast and slow twitch muscle of rat. In: Molecular basis of nerve activity (Changeux J-P, Hucho F, Maelicke A, Neumann E, eds), pp 567-588. Berlin: Walter de Gruyter.

Dolenc I, Črne-Finderle N, Eržen I, Sketelj J (1994) Satellite cells in slow and fast rat muscles differ in respect to acetylcholinesterase regulation mechanisms they convey to their myofibers during regeneration. J Neurosci Res 37:236-246.

Dupret JM, Brun P, Thomasset M (1986) In vivo effects of transcriptional and translational inhibitors on duodenal vitamin D-dependent calcium-binding protein messenger ribonucleic acid stimulation by $1,25-$ dihydroxycholecalciferol. Endocrinology 119:2476-2483.

Duval N, Krejci E, Grassi J, Coussen F, Massoulié J, Bon S (1992) Molecular architecture of acetylcholinesterase collagen-tailed forms; construction of a glycolipid-tailed tetramer. EMBO J 11:3255-3261.

Eccles JC, Katz B, Kuffler SW (1942) Effect of eserine on neuromuscular transmission. J Neurophysiol 5:211-230.

Falls DL, Rosen KM, Corfas G, Lane WS, Fischbach GD (1993) ARIA, a protein that stimulates acetylcholine receptor synthesis, is a member of the Neu ligand family. Cell 72:801-815.

Fambrough DM (1970) Acetylcholine sensitivity of muscle fiber membranes: mechanism of regulation by motoneurons. Science 163:372-373.

Fernandez HL, Hodges-Savola CA (1992) Trophic regulation of acetylcholinesterase isoenzymes in adult mammalian skeletal muscles. Neurochem Res 17:115-124.

Fernandez HL, Inestrosa NC, Stiles JR (1984) Subcellular localization of acetylcholinesterase molecular forms in endplate regions of adult mammalian skeletal muscle. Neurochem Res 9:1211-1230.

Fischbach GD, Robbins N (1969) Changes in contractile properties of disused soleus muscles. J Physiol (Lond) 201:305-320.

Fontaine B, Klarsfeld A, Hokfelt T, Changeux J-P (1986) Calcitonin gene-related peptide, a peptide present in spinal cord motoneurons, increases the number of acetylcholine receptors in primary cultures of chick embryo myotubes. Neurosci Lett 711:59-65.

Fuentes MA, Taylor P (1993) Control of acetylcholinesterase gene expression during myogenesis. Neuron 10:679-687.

Gisiger V, Belisle M, Gardiner PF (1994) Acetylcholinesterase adaptation to voluntary wheel running is proportional to the volume of activity in fast, but not slow, rat hindlimb muscles. Eur J Neurosci 6:673-680.

Groswald DE, Dettbarn W-D (1983) Characterization of acetylcholinesterase molecular forms in slow and fast muscle of rat. Neurochem Res 8:983-995.

Hall ZW (1973) Multiple forms of acetylcholinesterase and their distribution in endplate and non-endplate regions of rat diaphragm muscle. J Neurobiol 4:343-361.

Hall-Craggs ECB (1974) Rapid degeneration and regeneration of a whole skeletal muscle following treatment with bupivacaine (Marcaine). Exp Neurol 43:349-354.

Hansen-Smith FM, Carlson BM (1979) Cellular responses to free grafting of the extensor digitorum longus muscle of the rat. J Neurol Sci 41:149-173.

Harris DA, Falls DL, Dill-Devor RM, Fischbach GD (1988) Acetylcholine receptor-inducing factor from chicken brain increases the level of mRNA encoding the receptor $\alpha$ subunit. Proc Natl Acad Sci USA 85:1983-1987.

Hennig R, Lømo T (1985) Firing pattern of motor units in normal rats. Nature 314:164-166
Hník P, Škorpil V (1962) Fibrillation activity in denervated muscle. In: The denervated muscle (Gutmann E, ed), pp 135-150. Prague: Czechoslovak Academy of Sciences.

Hodges-Savola CA, Fernandez HL (1995) A role for calcitonin generelated peptide in the regulation of rat skeletal muscle $\mathrm{G}_{4}$ acetylcholinesterase. Neurosci Lett 190:117-120.

Inestrosa NC, Parelman A (1990) Association of acetylcholinesterase with the cell surface. J Membr Biol 118:1-9.

Jasmin BJ, Lee RK, Rotundo RL (1993) Compartmentalization of acetylcholinesterase mRNA and enzyme at the vertebrate neuromuscular junction. Neuron 11:467-477.

Kirschbaum BJ, Kucher H-B, Termin A, Kelly AM, Pette D (1990) Antagonistic effects of chronic low frequency stimulation and thyroid hormone on myosin expression in rat fast-twitch muscle. J Biol Chem 265:13974-13980.

Koenig J, Rieger F (1981) Biochemical stability of the AChE molecular forms after cytochemical staining: postnatal focalization of the $16 \mathrm{~S}$ AChE in rat muscle. Dev Neurosci 4:249-257.

Krejci E, Coussen F, Duval N, Chatel J-M, Legay C, Puype M, Vandekerckhove J, Cartaud J, Bon S, Massoulié J (1991) Primary structure of a collagenic tail peptide of Torpedo acetylcholinesterase: coexpression with catalytic subunit induces the production of collagentailed forms in transfected cells. EMBO J 10:1285-1293.

Krejci E, Thomine S, Boschetti N, Legay C, Sketelj J, Massoulie J (1997) The mammalian gene of acetylcholinesterase-associated collagen. J Biol Chem 272:22840-22847.

Lai J, Jedrzejczyk J, Pizzey JA, Green D, Barnard EA (1986) Neural control of the forms of acetylcholinesterase in slow mammalian muscles. Nature 321:72-74.

Legay C, Huchet M, Massoulié J, Changeux J-P (1995) Developmental regulation of acetylcholinesterase transcripts in the mouse diaphragm: alternative splicing and focalization. Eur J Neurosci 7:1803-1809.

Lømo T, Massoulié J, Vigny M (1985) Stimulation of denervated rat soleus muscle with fast and slow activity patterns induces different expression of acetylcholinesterase molecular forms. J Neurosci 5:1180-1187.

Magazanik LG, Fedorov VV, Giniatullin RA, Nikolsky EE (1984) Functional role of cholinesterase in different types of neuro-muscular junction. In: Cholinesterases: fundamental and applied aspects (Brzin M, Barnard EA, Sket D, eds), pp 229-242. Berlin: Walter de Gruyter.

Marnay A, Nachmansohn D (1938) Choline esterase in voluntary muscle. J Physiol (Lond) 92:37-47.

Massoulié J, Bon S (1982) The molecular forms of cholinesterase and acetylcholinesterase in vertebrates. Annu Rev Neurosci 5:57-106.

Michel RN, Vu CQ, Tetzlaff W, Jasmin BJ (1994) Neural regulation of acetylcholinesterase mRNAs at mammalian neuromuscular synapses. J Cell Biol 127:1061-1069.

Navarrete R, Vrbovà G (1983) Changes of activity patterns in slow and fast muscles during postnatal development. Dev Brain Res 8:11-19.

New HV, Mudge AW (1986) Calcitonin gene-related peptide regulates muscle acetylcholine receptor synthesis. Nature 323:809-811.

Pette D, Staron RS (1990) Cellular and molecular diversities of mammalian skeletal muscle fibers. Rev Physiol Biochem Pharmacol 116:1-76.

Pette D, Staron RS (1997) Mammalian skeletal muscle fiber type transitions. Int Rev Cytol 170:143-223.

Pette D, Vrbovà G (1992) Adaptation of mammalian skeletal muscle fibers to chronic electrical stimulation. Rev Physiol Biochem Pharmacol 120:115-220.

Pette D, Vrbovà G (1994) Transformation of skeletal muscle induced by electrical stimulation. Ann Card Surg 7:14-21.

Pun S, Tsim KW (1995) Truncated form of pro-acetylcholine receptorinducing activity (ARIA) induces AChR $\alpha$-subunit but not AChE transcripts in cultured chick myotubes. Neurosci Lett 198:107-110.

Purves D, Sakmann B (1974) The effect of contractile activity on fibrillation and extrajunctional acetylcholine-sensitivity in rat muscle maintained in organ culture. J Physiol (Lond) 237:157-182.

Ribarič S, Peterec D, Sketelj J (1996) Computer aided data acquisition and analysis of acetylcholinesterase velocity sedimentation profiles. Comput Methods Programs Biomed 49:149-156.

Rossi SG, Rotundo RL (1996) Transient interactions between collagentailed acetylcholinesterase and sulfated proteoglycans prior to immobilization on the extracellular matrix. J Biol Chem 271:1979-1987.

Rotundo RL, Rossi SG, Anglister L (1997) Transplantation of quail 
collagen-tailed acetylcholinesterase molecules onto the frog neuromuscular synapse. J Cell Biol 136:367-374.

Rubin LL, Chalfin NA, Adamo A, Klymkovsky MW (1985) Cellular and secreted forms of acetylcholinesterase in mouse muscle culture. J Neurochem 45:1932-1940.

Salafsky B, Bell J, Prewitt MA (1968) Development of fibrillation potentials in denervated fast and slow skeletal muscle. Am J Physiol 215:637-643

Schiaffino S, Gorza L, Aussoni S, Botinelli R, Reggiani C, Larson L, Edström L, Gundersen K, Lømo T (1990) Muscle fiber types expressing different myosin heavy chain isoforms: the functional properties and adaptive capacity. In: The dynamic state of muscle fibers (Pette D, ed), pp 329-341. Berlin: Walter de Gruyter.

Shapira M, Seidman S, Sternfeld M, Timberg R, Kaufer D, Patrick J, Soreq H (1994) Transgenic engineering of neuromuscular junctions in Xenopus laevis embryos transiently overexpressing key cholinergic proteins. Proc Natl Acad Sci USA 91:9072-9076.

Simoneau J-A, Pette D (1988) Species specific effects of chronic nerve stimulation upon tibialis anterior muscle in mouse, rat, guinea pig, and rabbit. Pflügers Arch 412:86-92.

Sketelj J (1994) Neural regulation of acetylcholinesterase in skeletal muscles. BAM 4:281-291.

Sketelj J, Brzin M (1985) Asymmetric molecular forms of acetylcholinesterase in mammalian skeletal muscle. J Neurosci Res 14:95-103.

Sketelj J, Crešnar B (1995) Neural regulation of acetylcholinesterase expression in slow and fast muscles of the rat. In: Enzymes of the cholinesterase family (Quinn DM, Balasubramanian AS, Doctor BP, Taylor P, eds), pp 253-260. New York: Plenum.

Sketelj J, Crne N, Brzin M (1987) Molecular forms and localization of acetylcholinesterase and nonspecific cholinesterase in regenerating skeletal muscles. Neurochem Res 12:159-165.

Sketelj J, Črne N, Ribarič S, Brzin M (1991) Interactions between in- trinsic regulation and neural modulation of acetylcholinesterase in fast and slow skeletal muscle. Cell Mol Neurobiol 11:35-54.

Sketelj J, Črne-Finderle N, Brzin M (1992a) Influence of denervation on the molecular forms of junctional and extrajunctional acetylcholinesterase in fast and slow muscles of the rat. Neurochem Int 21:415-421.

Sketelj J, Črne-Finderle N, Dolenc I (1992b) Factors influencing acetylcholinesterase regulation in slow and fast skeletal muscles. In: Multidisciplinary approaches to cholinesterase functions (Shafferman A, Velan B, eds), pp 209-216. New York: Plenum.

Sketelj J, Crne-Finderle N, Sket D, Dettbarn W-D, Brzin M (1993) Comparison between the effects of botulinum toxin-induced paralysis and denervation on molecular forms of acetylcholinesterase in muscles. J Neurochem 61:501-508.

Sketelj J, Leisner E, Gohlsch B, Škorjanc D, Pette D (1997) Specific impulse patterns regulate acetylcholinesterase activity in skeletal muscles of rats and rabbits. J Neurosci Res 47:49-57.

Snoj-Cvetko E, Smerdu V, Sketelj J, Dolenc I, d'Albis A, Janmot C, Eržen I (1996) Adaptive range of myosin heavy chain expression in regenerating soleus is broader than in mature muscle. J Muscle Res Cell Motil 17:401-409.

Sugiyama H (1977) Multiple forms of acetylcholinesterase in clonal muscle cells. FEBS Lett 84:257-260.

Termin A, Staron RS, Pette D (1989) Changes in myosin heavy chain isoforms during chronic low-frequency stimulations of rat fast hind limb muscles: a single fiber study. Eur J Biochem 186:749-754.

Tyler KR, Wright AJA (1980) Light weight portable stimulators for stimulation of skeletal muscles at different frequencies and for cardiac pacing. J Physiol (Lond) 307:6P-7P.

Westgaard RH, Lømo T (1988) Control of contractile properties within adaptive ranges by patterns of impulse activity in the rat. J Neurosci $8: 4415-4426$ 